\title{
KARAKTER TOKOH HAYAM WURUK
}

\author{
Beni Suprianto ${ }^{1)}$, Santi Sidhartani ${ }^{2)}$ \\ Program Studi Desain Komunikasi Visual, \\ Fakultas Bahasa dan Seni, Universitas Indraprasta PGRI \\ Jl. Nangka No. 58 C, Tanjung Barat, Jakarta 12530, Indonesia \\ beni.kumbang@gmail.com
}

\begin{abstract}
Abstrak
Majapahit adalah salah satu kerajaan terbesar yang ada di bumi nusantara yang berdiri sekitar tahun 1293 hingga 1500 M. Kerajaan Majapahit mencapai puncak kejayaan di era kepemimpinan raja ke empat yaitu Hayam Wuruk yang berkuasa dari tahun 1350 sampai dengan 1389. Perancangan Karakter Tokoh Hayam Wuruk ditujukan untuk anak-anak, agar anak-anak memahami tentang sejarah, khususnya tokoh-tokoh penting dalam sejarah tersebut. Lebih khususnya lagi tentang sejarah keberadaan Hayam Wuruk sebagai raja keempat Majapahit yang membawa Majapahit pada puncak kejayaan. Animasi sebagai media kreatif sangat digemari oleh anak-anak karena tersaji dengan audio-visual sehingga lebih mudah diingat dan menarik. Melalui film animasi, selain dapat mengenalkan Hayam Wuruk sebagai raja keempat Majapahit, juga meningkatkan ketertarikan dan keingintahuan anak-anak pada budaya local. Dapat juga menjadi media edukasi dan hiburan yang bisa mengerakkan para anak-anak untuk kreatif. Oleh sebab itu, ke depannya dalam mengembangkan film animasi dapat mengadaptasi budaya lokal sehingga menjadi konten global yang diminati di seluruh dunia.
\end{abstract}

Kata Kunci: Karakter visual, tokoh, Hayam Wuruk

\begin{abstract}
Majapahit is one of the largest kingdoms in the archipelago which was established around 1293 to 1500 M. The kingdom of Majapahit reached its peak in the era of the fourth king's leadership, Hayam Wuruk, who ruled from 1350 to 1389. The designation of Character Hayam Wuruk was intended to children so that children understand history, especially important figures in that history. More specifically again about the history of the existence of Hayam Wuruk as the fourth king of Majapahit who brought Majapahit at the height of its glory. Animation as a creative medium is very popular with children because it is presented with audio-visual making it more memorable and interesting. Through animated films, besides being able to introduce Hayam Wuruk as the fourth king of Majapahit, it also increases children's interest and curiosity in the local culture. Can also be a medium of education and entertainment that can mobilize children to be creative. Therefore, in the future in developing animated films can adopt local culture to become global content that is in demand throughout the world.
\end{abstract}

Keywords: Visual characters, figures, Hayam Wuruk.

\section{PENDAHULUAN}

Hayam Wuruk bergelar Sri Rajasanagara adalah Raja Majapahit keempat yang dinobatkan pada tahun 1350 M (Wiwoho, 1982: 24). Sejak usia enam belas tahun Hayam Wuruk telah menjadi raja. Pada masa Pemerintahanya Majapahit mengalami puncak kejayaan (1313-1364 M) (Khozi, Alhaddar, 2016: 1439). 
Beberapa hal penting yang menunjukkan kejayaan Majapahit di antaranya adanya sistem pemerintahan yang aktif, adanya kestabilan pemerintahan, terselenggaranya upacara megah di istana, tumbuh-kembangnya berbagai bentuk kesenian, hidupnya perniagaan nusantara dengan Majapahit, berlangsungnya kehidupan beragama dengan baik, pelaksanaan politik Majapahit dengan nusantara, dan adanya pengakuan Internasional terhadap Majapahit (Hernawan, 2011: 39).

Hayam Wuruk adalah salah satu tokoh Majapahit yang kurang populer di masyarakat, khususnya anak-anak. Untuk memperkenalkan karakter Hayam Wuruk kepada masyarakat dibutuhkan proses. Untuk menumbuhkan minat mempelajari sejarah terutama anak-anak, maka diperlukan media interaktif film animasi yang akan memudahkan dalam memahami karakter tokoh Hayam Wuruk. Film animasi banyak disukai anak-anak karena menggunakan bahasa verbal dan bahasa gambar sehingga memudahkan untuk memahami pesan yang disampaikan (Ulfa, 2017:6).

Film animasi adalah media kreatif yang dapat digunakan untuk menggambarkan apa pun peristiwa yang pernah terjadi sebagai media pengingat dan pembelajaran. Dalam pembuatan film animasi dibutuhkan perancangan karakter tokoh utama yang kuat untuk menjadi tokoh sentral dalam suatu cerita. Hal itu dikarenakan tokoh selalu mempunyai peran penting dalam menyampaikan suatu pesan.

Kekuatan visual mampu membangun persepsi penonton film animasi melalui elemen desain pada karakter visual. Karakter dapat mencakup budaya dan berpotensi menjadi produk simbolik pembawa pesan budaya (Pratama, Wardani, dan Akbar, 2017:207). Oleh sebab itu, diperlukan perancangan karakter tokoh tentang sejarah Indonesia yang mampu mejadi media penyampai pesan. Hal itu untuk merespon adanya serbuan dan menjamurnya film-film dari luar atau bangsa lain yang mengangkat tentang cerita rakyat, mitologi, dan legenda yang mengakibatkan kalangan remaja lebih mengenal budaya luar daripada budaya Indonesia.

\section{METODE PENELITIAN}

Pengumpulan data didapatkan dari studi literatur, observasi, dan wawancara. Studi literatur didapatkan dari pustaka yang relevan dan observasi sekaligus wawancara kepada narasumber, yaitu Prof. Dr. Agus Aris Munandar, M.Hum yang merupakan seorang arkeolog. Hasil dari observasi dan wawancara adalah gambaran karakter Hayam Wuruk. Selain karakter, penulis juga menggali tentang warna-warna pada pakain yang digunakan kala itu dan latar belakang atau suasana pada masa Majapahit. Data yang berhasil dikumpulkan akan menjadi dasar untuk menentukan konten/materi pada film animasi, khususnya sebagai acuan perancangan karakter visual dari tokoh Hayam Wuruk.

\section{HASIL DAN PEMBAHASAN}

\section{Film Animasi}

Animasi berasaal dari kata to animate yang artinya membuat seolah-olah hidup bergerak. Pengertian animasi adalah gambar-gambar yang diolah sedemikian rupa hingga menjadi sebuah gambar bergerak dan bercerita. Secara umum animasi dibagi menjadi dua, yaitu animasi 2D (dua dimensi) dan animasi 3D (tiga dimensi) (Gunawan, 2013:26). Berdasarkan uraian tersebut animasi adalah kumpulan dari gambar-gambar yang bergerak dan memiliki alur cerita yang bermakna.

Nantinya film animasi yang akan dirancang adalah film animasi dua dimensi, yaitu teknik pembuatan animasi dengan menggunakan gambar bersumbu (axis) dua yaitu $\mathrm{X}$ dan $\mathrm{Y}$. Animasi ini lebih dikenal dengan animasi manual yang prosesnya dimulai dengn mengambar di atas selembar gambar, lalu di-scan dan dipindahkan ke dalam komputer untuk diubah menjadi file digital (Gunawan, 2013:27).

\section{Karakter Visual}


Dalam proses pembuatan film animasi, pembuatan karakter mengacu kepada naskah penulisan film animasi. Kemudian naskah tersebut dipahami dan dibuat catatan yang selanjutnya diilustrasikan dalam beberapa kebutuhan karakter yang ada.

Untuk menentukan unsur-unsur internal karakter. Bentuk tidak hanya dapat menghasilkan penampilan yang khas karakter, tetapi juga konotasi jenis karakter pribadi. Elemen tekstur desain adalah fisik permukaan bahan dapat dirasakan dengan indra peraba. Elemen tesktur adalah keadaan fisik permukaan bahan yang dapat diraba dan dirasakan dengan indra peraba atau dapat dirasakan dengan indra penglihatan seperti tekstur terlihat (Irawan dalam Pratama, Wardani dan Akbar, 2018:88).

Desain karakter dapat diciptakan melalui element desain line, yaitu untuk memvisualisasikan bentuk melalui jenis, ketebalan, orientasi, dan posisi dalam menyajikan ke pribadian, ekspresi, emosi, jenis kelamin, dan kelas sosial. Kemudian, untuk memperkuat karakter visual, penting ditambahkan elemen visual tekstur dan warna sebagai dari hasil gambar yang seolah-olah dua dimensi (Pratama, Wardani, dan Akbar, 2017:296)

Elemen desain warna adalah efek dari tanda yang digunakan mewakili apa saja yang di nilai tepat. Secara simbolis, warna tanda visual digunakan untuk tujuan konotatif. Makna sensoris dan emosional yang melekat pada warna. Dengan kata lain, melalui warna, seseorang dapat merasakan warna lebih dari sebuah fenomena yang melibatkan persepsi visual saja. Khususnya dalam budaya masyarakat, warna memainkan fungsi yang sangat penting di bidang simbolisme. Elemen warna dapat menjadi signifikansi penting untuk membawa pesan dan makna (Danesi dalam Pratama, Wardani, dan Akbar, 2018:88).

\section{Tokoh Hayam Wuruk}

Hayam Wuruk mempunyai makna 'ayam terpelajar' adalah putra dari Tribhuwana Tuggadewi dan Sri Khertawardhana. Saat kelahiran Hayam Wuruk disambut dengan gempa bumi, hujan lebat, dan meletusnya Gunung Kampud (Riana, 2009:31).

Sosok Hayam Wuruk adalah raja yang tegas dan pemberani, Hayam Wuruk sangat pandai dalam ilmu kepemerintahaan sehingga selama kepemerintahan Hayam Wuruk tidak pernah terjadi gejolak internal maupun eksternal yang dapat merusak tatanan kepemerintahan Hayam Wuruk (Munandar, wawancara pada tanggal 23 oktober 2018).

Berikut beberapa hal penting yang menunjukkan kejayaan Majapahit, di antaranya:

1. Adanya sistem pemerintahan yang aktif dengan ditandai dengan penerimaan upeti dan utusan dari daerah-daerah di seluruh pelosok Nusantara dan penerimaan utusan dari internasional. Selain menerima utusan pemerintahan Hayam Wuruk juga mengirimkan utusan setiap tahunnya kepada raja-raja di seluruh nusantara dan internasioal.

2. Kestabilan pemerintahan Majapahit di masa pemerintahan Hayam Wuruk ditandai dengan tidak adanya konflik internal ataupun eksternal dengan daerah-daerah lainnya.

3. Terselenggaranya upacara megah setiap setahun sekali di Istana Majapahit.

4. Berkembangnya kesenian.

5. Hidupnya perniagaan Nusantara dengan Majapahit ditandai dengan perjalanan armada dagang Majapahit yang megah ke seluruh pesolok Nusantara.

6. Terselenggaranya upacara-upacara besar keagamaan.

7. Adanya pengakuan internasional terhadap Majapahit.

Tidak banyak ditemukan referensi karakter tentang pengembangan visual Hayam Wuruk, tetapi penulis dapat menyimpulkan pengambaran visual Hayam Wuruk dari hasil wawancara dengan Prof. Dr. Agus Aris Munandar, M.Hum, yaitu Hayam Wuruk adalah sosok berbadan tegap dengan dada bidang, memiliki mata yang tidak sipit, dan mempunyai tatapan mata yang tajam, rambut panjang yang selalu tergulung rapi di balik mahkota.

Hayam Wuruk pada saat suasana resmi menggunakan pakaian berwarna biru, cokelat, dan putih. Pada bagian atas bertelanjang dada dengan dihiasai kalung berwarna emas dan pada bagian kedua tangan terdapat juga gelang-gelang berwarna emas. Selain kalung dan gelang juga terdapat kain panjang yang diselempangkan di dada, sedangkan pakaian bagian bawah Hayam Wuruk 
menggunakan celana pendek yang dibalut dengan kain (Munandar, wawancara pada tanggal 14 juli 2018).

\section{Perancangan Karakter Visual Hayam Wuruk}

Berdasarkan data di atas dapat dijadikan dasar perancangan desain karakter Hayam Wuruk. Dalam pembuatan perancangan karakter Hayam Wuruk tetap akan merujuk pada data-data yang telah dikumpulkan lalu dibuat dengan pengayaan kartun, yang mengambarkan sosok laki-laki yang tampan, badan bidang seperti raja-raja pada umumnya dan terlihat lebih lucu.

Target audiens lebih difokuskan kepada anak-anak dengan usia 9-11 tahun yang senang dan gemar menonton animasi. Dengan karakter tokoh Film animasi yang sesuai dengan segmennya, diharapkan dapat memperkenalkan tokoh sejarah lebih efektif dan lebih menyenangkan dan dapat menyampaikan informasi kepada para penonton.

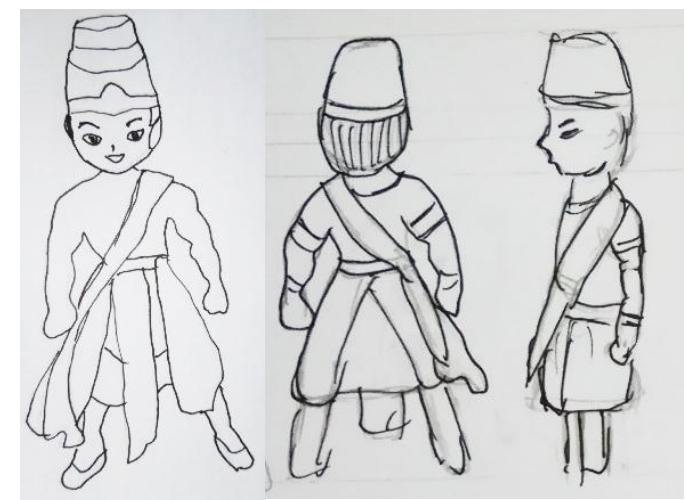

Gambar 1 Sketsa Kasar Karakter Hayam Wuruk Sumber: Dokumen Pribadi, 2018

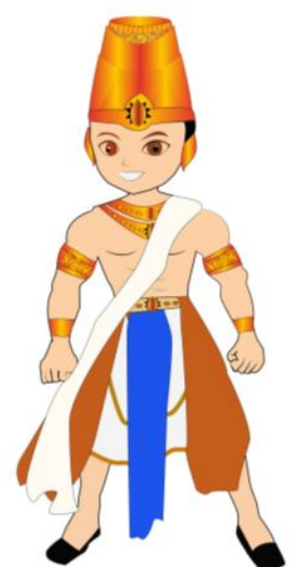

Gambar 2 Karakter Hayam Wuruk

Sumber: Dokumen Pribadi, 2018

\section{SIMPULAN}

Perancangan Karakter Tokoh Hayam Wuruk ditujukan untuk anak-anak, agar anak-anak memahami tentang sejarah, khususnya tokoh-tokoh penting dalam sejarah tersebut. Lebih khususnya lagi tentang sejarah keberadaan Hayam Wuruk sebagai raja keempat Majapahit yang membawa Majapahit pada puncak kejayaan.

Animasi sebagai media kreatif sangat digemari oleh anak-anak karena tersaji dengan audio-visual sehingga lebih mudah diingat dan menarik. Melalui film animasi, selain dapat 
mengenalkan Hayam Wuruk sebagai raja keempat Majapahit, juga meningkatkan ketertarikan dan keingintahuan anak-anak pada budaya local. Dapat juga menjadi media edukasi dan hiburan yang bisa mengerakkan para anak-anak untuk kreatif. Oleh sebab itu, ke depannya dalam mengembangkan film animasi dapat mengadaptasi budaya lokal sehingga menjadi konten global yang diminati di seluruh dunia

\section{DAFTAR PUSTAKA}

Gunawan, B. B. (2013). Nganimasi bersama Mas Be! Jakarta: PT Elex Media Komputindo

Hernawan, W. (2011). Perang bubat dalam literatur Majapahit. Jurnal Wawasan, Jurnal Agama dan Sosial Budaya, 34(1), 1-104.

Pratama, D., Wardani, W. G. W., \& Akbar, T. (2018). Designing visual character of Gajah Mada and Tribhuwana Tunggadewi as representation of historical figures in visual novel. Humanus, 17 (1), 84-96.

Pratama, D, Wardani, W.G.W., \& Akbar, T. (2017). Designing visual character of Raden Wijaya as historical figure in visual novel. Jurnal International of scientific \& Tecnology Research, 6(11), 207-210.

Ulfa, A. N. (2017). Pengembangan film animasi dengan materi perkembangan kerajan-kerjaan Islam di Indonesia sebagai sumber IPS SMP VII. Fakultas Ilmu Sosial, Universitas Negeri Jogyakarta.

Wiwoho, R. H. (1982). Tinjauan kembali atas tokoh Hayam Wuruk dan Gajah Mada. Jurusan Ilmu-ilmu Sejarah Seksi Arkeologi, Fakultas Sastra, Universitas Indonesia, Jakarta. 